\title{
Nanostructures of n-type Organic Semiconductor in a p-type Matrix via Self-Assembly of Block Copolymers
}

\author{
Stefan M. Lindner and Mukundan Thelakkat* \\ Makromolekulare Chemie I, Universität Bayreuth, Universitätsstrasse 30, 95440 Bayreuth, \\ Germany
}

\section{Supporting Information}

General Information. The initiator $\mathbf{1}$ and the free nitroxide $\mathbf{3}$ were prepared according to literature $^{1}$. The monomer 5 was prepared by a similar procedure as for unsymetrically substituted perylene bisimides according to literature ${ }^{2,3}$. The free nitroxide 3 and $\mathrm{P}\left({ }^{\mathrm{t}} \mathrm{Bu}\right)_{3}$ were added as stock solutions in the solvent used for reaction. o-dichlorobenzene (water free) was purchased from Aldrich, anisole and toluene were distilled over sodium in an argon atmosphere and acetone was distilled over $\mathrm{CaCl}_{2}$. Conversion and dye content were determined using ${ }^{1} \mathrm{H}$ NMR. ${ }^{1} \mathrm{H}$ NMR spectra were acquired on a Bruker AC 250 spectrometer (250 MHz). The molecular weights of polymers were determined by gel permeation chromatography $(\mathrm{GPC})$ in THF $+0.25 \mathrm{wt} \%$ tetrabutylammonium bromide with UV and RI detectors (Waters) using polystyrene standards for calibration. UV/vis spectra were recorded using a Hitachi U-3000 spectrometer. Fluorescence spectra were recorded using a Shimadzu RF-5301 PC Spectrofluorophotometer. The thermal degradation of polymers was studied using a Mettler Toledo TGA/SDTA $851^{\mathrm{e}}$ with a heating rate of $10 \mathrm{~K} / \mathrm{min}$ under $\mathrm{N}_{2}$ 
atmosphere and the differential scanning calorimetry was carried out with a Perkin Elmer Diamond DSC with a heating rate of $10 \mathrm{~K} / \mathrm{min}$ under $\mathrm{N}_{2}$ atmosphere. TEM measurements were performed on a Zeiss 902 at $80 \mathrm{kV}$, the samples were stained with $\mathrm{RuO}_{4}$.

Synthesis of 2. A mixture of diphenylamine (6.77 g, $40 \mathrm{mmol})$, 4-bromostyrene (8.79 g, 48 mmol), sodium tert-butoxide $(5.00 \mathrm{~g}, 52 \mathrm{mmol}), \mathrm{Pd}(\mathrm{OAc})_{2}(90 \mathrm{mg}, 0.4 \mathrm{mmol})$ and $\mathrm{P}\left({ }^{\mathrm{t}} \mathrm{Bu}\right)_{3}$ $(0.324 \mathrm{~g}, 1.6 \mathrm{mmol})$ in $40 \mathrm{ml}$ toluene under argon was heated at $100{ }^{\circ} \mathrm{C}$ for $1 \mathrm{~h}$. Column chromatography (silica gel, hexanes) afforded $9.22 \mathrm{~g}(85 \%)$ of product 2.

Synthesis of 4A and 4B. A mixture of 1 (32.55 mg, $0.1 \mathrm{mmol}), 3(1.10 \mathrm{mg}, 0.005 \mathrm{mmol}), 2$ (5.430 g, $20 \mathrm{mmol}$ ) and $1000 \mu \mathrm{l}$ anisole were degassed by two freeze/thaw cycles, sealed under argon, and heated at $125^{\circ} \mathrm{C}$ for $1 \mathrm{~h}(\mathbf{4 A})$ or $2 \mathrm{~h}(\mathbf{4 B})$. The reaction mixture was cooled, dissolved in THF and precipitated (2 times) in methanol. The white precipitate was filtered and dried to give the desired macroinitiator 4A $(2.438 \mathrm{~g})$ or $\mathbf{4 B}(3.910 \mathrm{~g})$.

Synthesis of 6A and 6B. A mixture of the macroinitiator 4A $(194 \mathrm{mg}), \mathbf{5}(495 \mathrm{mg}, 0.6$ mmol), 3 (0.11015 mg, $0.0005 \mathrm{mmol})$ and $250 \mu \mathrm{l}$ o-dichlorobenzene were degassed by two freeze/thaw cycles, sealed under argon, and heated at $125^{\circ} \mathrm{C}$ for $8 \mathrm{~h}(\mathbf{6 A})$ or $24 \mathrm{~h}(\mathbf{6 B})$. The reaction mixture was cooled, dissolved in THF and precipitated (3 times) in acetone. The red precipitate was filtered and dried to give the desired blockcopolymer 6A (207 mg) or 6B (298 $\mathrm{mg})$. 
Synthesis of 6C. A mixture of 4A (194 mg), 5 (990 mg, $1.2 \mathrm{mmol}), 3$ (0.11015 mg, 0.0005 mmol) and $250 \mu \mathrm{lo}$-dichlorobenzene were degassed by two freeze/thaw cycles, sealed under argon, and heated at $125{ }^{\circ} \mathrm{C}$ for $24 \mathrm{~h}$. The reaction mixture was cooled, dissolved in THF and precipitated (3 times) in acetone. The red precipitate was filtered and dried to give the desired block copolymer 6C (479 mg).

Synthesis of 7. A mixture of 1 (6.51 mg, $0.02 \mathrm{mmol}), \mathbf{3}(0.2203 \mathrm{mg}, 0.001 \mathrm{mmol}), \mathbf{5}(660 \mathrm{mg}$, $0.8 \mathrm{mmol}$ ) and $500 \mu \mathrm{l}$ anisole were degassed by two freeze/thaw cycles, sealed under argon, and heated at $125{ }^{\circ} \mathrm{C}$ for $1 \mathrm{~h}$. The reaction mixture was cooled, dissolved in THF and precipitated ( 2 times) in acetone. The red precipitate was filtered and dried to give the desired polymer 7 (384 mg). 

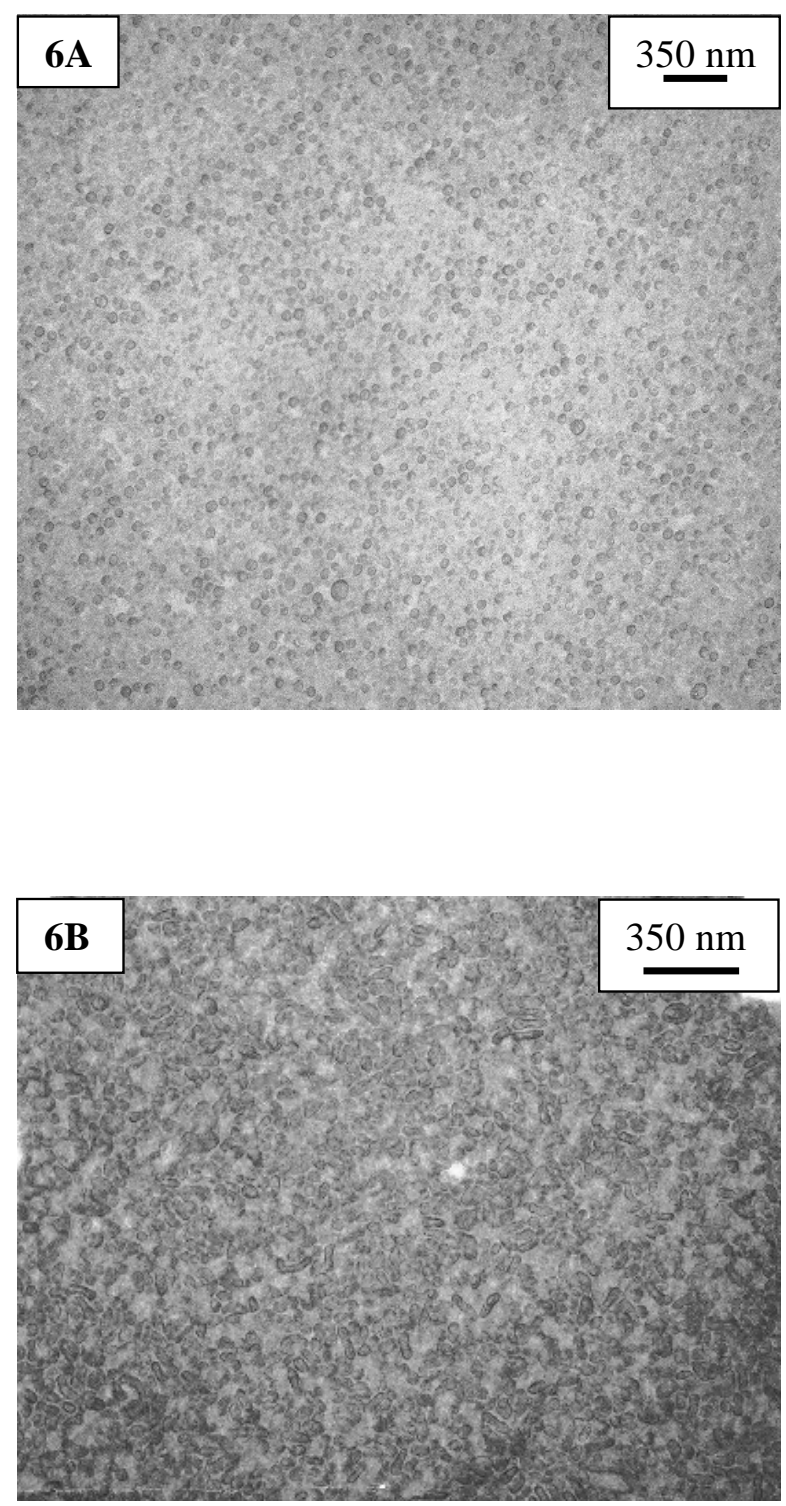

Figure 1. TEM of cross sections of $6 \mathbf{A}$ and $6 \mathbf{B}$ from relatively thick films obtained by melting down the polymers onto a glass substrate and subsequently tempering them at $200{ }^{\circ} \mathrm{C}$ for 1 hour. The growth of nanostructures can be seen from $6 \mathrm{~A}$ to $6 \mathrm{~B}$ in the order of increasing perylene dye content. 


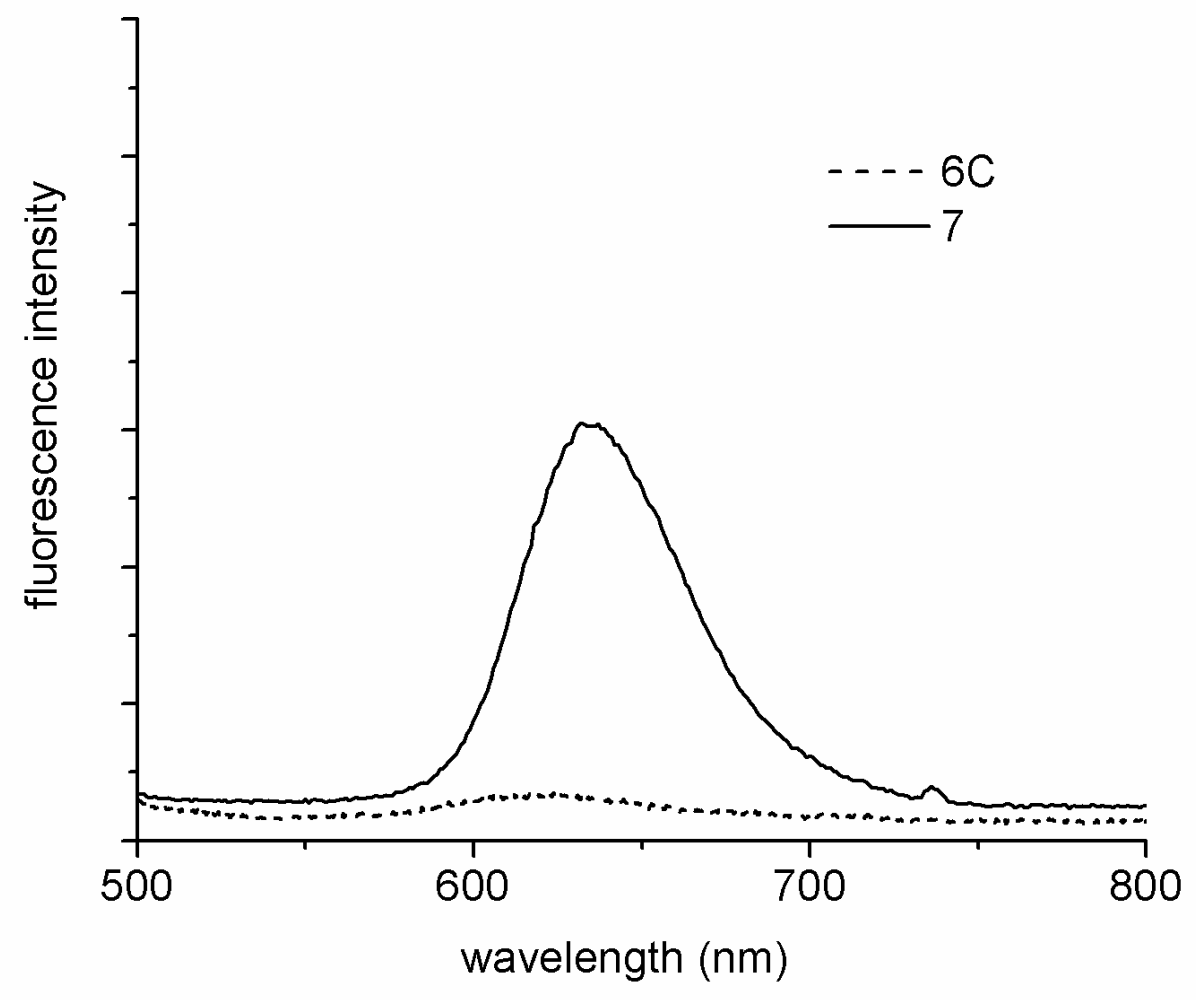

Figure 2. Fluorescence spectra of $\mathbf{7}$ and $\mathbf{6 C}$ measured in film by excitation at the absorption maximum of perylene at $492 \mathrm{~nm}$. At $632 \mathrm{~nm}$ the peak intensity due to perylene emission diminishes considerably in block copolymer 6C and the quenching efficiency is about $95 \%$.

1 Benoit, D.; Chaplinski, V.; Braslau, R.; Hawker, C. J. J. Am. Chem. Soc. 1999, 121, 3904-3920.

${ }^{2}$ Kaiser, H.; Lindner, J.; Langhals, H. Chem. Ber. 1991, 124, 529-535.

${ }^{3}$ Langhals, H.; Saulich, S. Chem. Eur. J. 2002, 8, 5630-5643. 